\title{
Monitoring and evaluation of thermal comfort in urban areas: application to Valencia city
}

\author{
David Alfonso-Solar ${ }^{1}$, Paula Bastida-Molina ${ }^{2}$, Lina Montuori ${ }^{1}$, Carlos Vargas- \\ Salgado ${ }^{2}$, \\ ${ }^{1}$ Department of Applied Thermodynamics, Universitat Politecnica de Valencia, Spain, \\ ${ }^{2}$ Department of Electrical Engineering, Universitat Politecnica de Valencia, Spain.
}

\begin{abstract}
In this paper, it is presented preliminary results of a methodology for thermal comfort monitoring and evaluation in urban areas based on local metering of ambient conditions and Rayman model application. In the framework of GROWGREEN European project it was installed six monitoring stations for data acquisition of air temperature, relative humidity, wind speed, solar radiation and black globe temperature. Data of first 5 months of monitoring and modelling of one location with Rayman model to calculate PET (physiological equivalent temperature) is presented. Based on PET it was calculated the percentage of hours with thermal comfort per month, and it was made a comparison between PET and black globe temperature (GT) in order to evaluate the suitability of GT as a single, low cost and robust indicator of thermal comfort in urban areas.
\end{abstract}

Keywords: thermal comfort; monitoring; Rayman model; black globe temperature 


\section{Introduction}

Climate change provides that heat stress periods frequency and intensity progressively increase, especially in warm climates as Mediterranean one. Additionally, big cities present the urban heat island effect so that built areas absorb more heat than natural areas (agricultural or forest areas) (Oke, 1982). These facts provide a significant health risk for the population (Rosenzweig et al , 2017) and comfort in outdoor areas is being reduced progressively and so, specific criteria and detailed information about urban thermal behaviour should be provided to urban management organizations (Blumberg, 2014 ; European Environment Agency, 2012). Urban planning, maintenance and refurbishment should use this information and focus on mitigating heat stress in warm climates cities.

GROW GREEN project through the delivery of four demonstration projects in a wide range of different geographical, climatic, political, governance, societal and financial scenarios, will establish the evidence that NBS $^{1}$ (Nature-based solutions) in cities provide a costeffective, sustainable and replicable alternative to improve urban climate and water resilience, and deliver social, environmental and economic benefits.

Valencia city, in the framework of GROW GREEN project ${ }^{2}$, will demonstrate, through specific pilot actions, the feasibility, multi-benefits and effectiveness of NBS for urban heat management.

In this work it is presented preliminary result of heat stress monitoring and modelling results for two locations. Specific climatic parameters (Temperature, humidity, solar radiation, wind speed, black globe temperature) metering results (since January 2019), and PET (Physiological Equivalent Temperature) modelling through RAYMAN model will be compared.

\section{Methodology}

For outdoor comfort evaluation, in two different urban locations in Valencia (Spain) city, it will be used PET (Physiologically Equivalent Temperature). The PET index has been used

\footnotetext{
${ }^{1}$ According to European Commission (EC) definition, Nature-based solutions are actions inspired by, supported by or copied from nature and which aim to help societies address a variety of environmental, social and economic challenges in sustainable ways.

2 Grant Agreement number: 730283 - GROW GREEN - H2020-SCC-2016-2017/H2020-SCC-NBS-2stage-2016. http://growgreenproject.eu/
} 
many times for urban bioclimatic studies (Matzarakis et al., 1999 ; Matzarakis and Endler, 2010) to evaluate outdoor comfort and heat stress.

In order to calculate PET values, which is a complex issue, it has been selected RAYMAN model (Matzarakis et al., 2007, 2010) software which facilitates these calculations based on accurate information about weather conditions and obstacles (buildings and trees).

For the evaluation of PET it is necessary local metering of air temperature, wind, relative humidity and solar radiation. Additionally it is needed information about obstacles for solar radiation as buildings and trees to evaluate heat stress indicators, as PET, using software RAYMAN model.

\subsection{Locations and monitoring equipment}

It has been selected one location with high insolation, location A (all obstacles with height lower than $25 \mathrm{~m}$ and at distances higher than $55 \mathrm{~m}$ ) in Figure 1, and another, location $\mathrm{B}$ partially shadowed due to many trees (height of about $12-20 \mathrm{~m}$ ) in the south according to observer (metering box) position (see Figure 2).

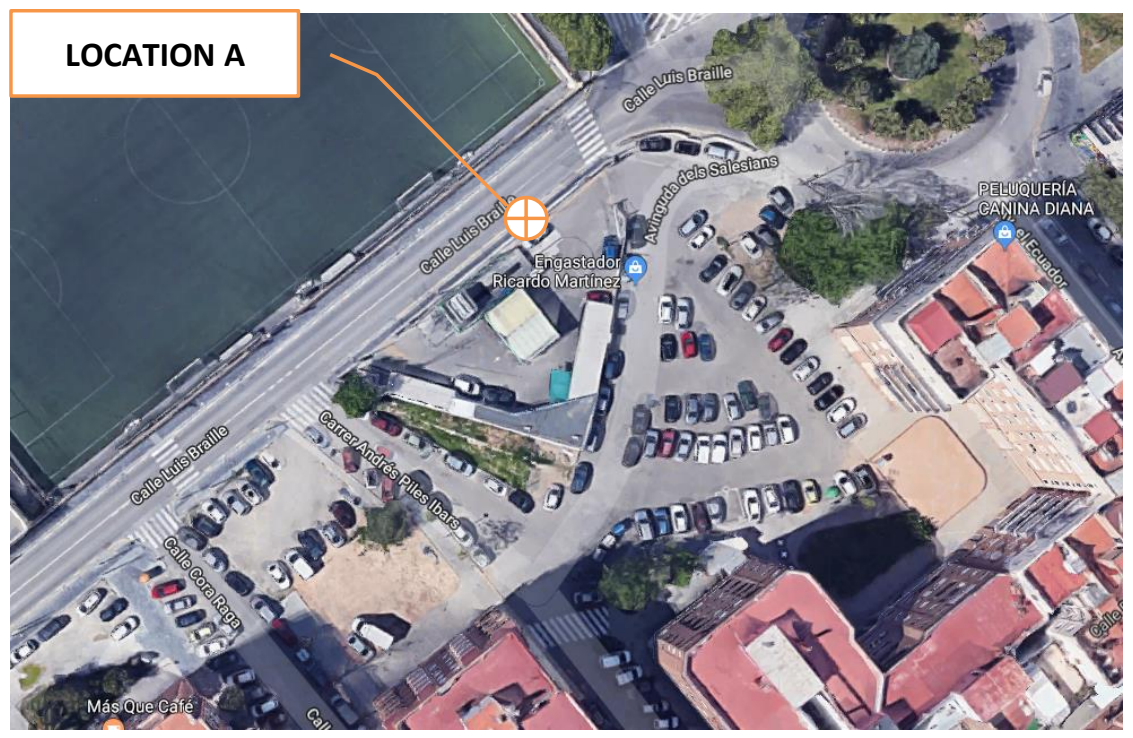

Figure 1. Location A: high insolation (Braile street, Valencia, Spain) 


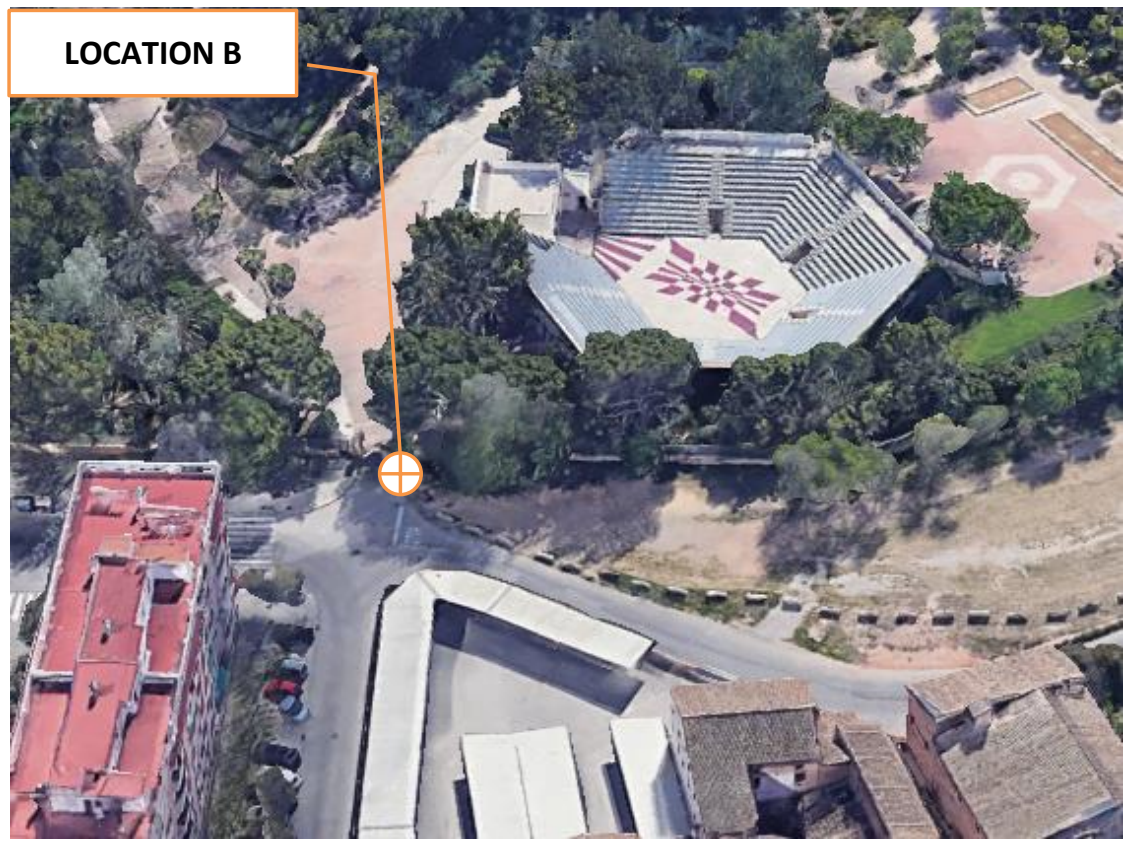

Figure 2. Location B: partial shadowing with trees (Andreu Alfaro street, Valencia, Spain)

For heat stress monitoring purposes it has been used a HSM (heat stress monitoring box), see Figure 3, with acquisition of data about black globe (BG) temperature, air temperature, humidity, wind speed and solar radiation. HSM boxes are attached to urban street lights posts and, always, south oriented.

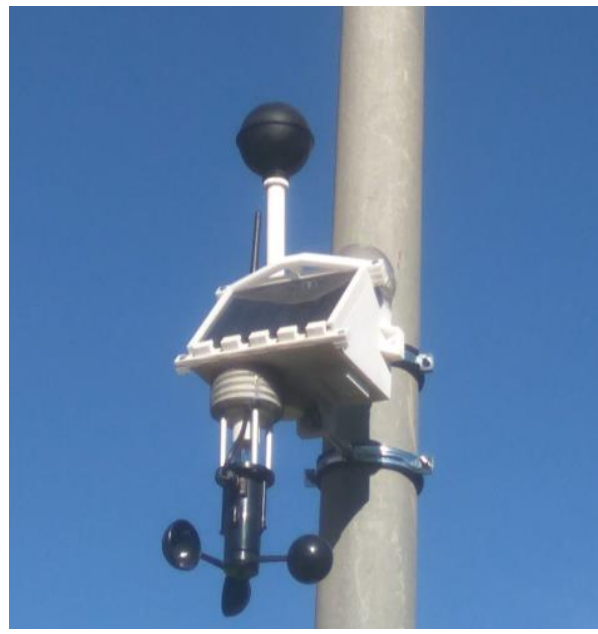

Figure 3. HSM - Heat stress monitoring box. 
In location A it has been checked that in Winter (January 2019) this box is metering undisturbed solar radiation from 9:00 in the morning to 18:00 in the afternoon, and so in summer (really may 2019) from 8:00 to 20:00.

Black globe ${ }^{3}$ temperature consists of a hollow copper sphere (90 $\mathrm{mm}$ diameter) painted matt black, to absorb radiant heat, with a temperature sensor at its centre.

\subsection{PET and Black globe evaluation and comparison}

Both locations will be modelled with RAYMAN model software to evaluate PET in each hour during 6 months (from January to June 2019), and direct metering of black globe temperature is provided by HSM boxes (also hourly). With PET hourly values it will be calculated thermal comfort hours according to the following reference table (Matzarakis et al.,1999):

Table 1. Thermal perception PET ranges.

\begin{tabular}{rrl}
\hline Max. & Min. & Thermal perception \\
\hline & $>41$ & Extreme heat stress \\
41 & 35 & Strong heat stress \\
35 & 29 & Moderate heat stress \\
29 & 23 & Slight heat stress \\
23 & 18 & No thermal stress \\
18 & 13 & Slight cold stress \\
13 & 8 & Moderate cold stress \\
8 & 4 & Strong cold stress \\
& $<4$ & Extreme cold stress \\
\hline
\end{tabular}

\footnotetext{
3 For further information please see ISO 7726. Ergonomics of the thermal environment - Instrument for measuring physical quantities". Geneva, Switzerland: International Organization for Standardization. November 1998.
} 
It will be compared, hour by hour, PET values with black globe (BG) temperature in order to evaluate the possibility of using BG as a single, simple and low cost indicator to monitor heat stress.

\section{Results and discussion}

In Table 2 it is included thermal perception hours evaluation in locations A and B (according to PET results):

Table 2 . Thermal perception hours

\begin{tabular}{lcccc} 
& \multicolumn{2}{c}{ LOCATION A } & \multicolumn{2}{c}{ LOCATION B } \\
\hline Thermal perception & Time(h) & $\%$ & Time(h) & $\%$ \\
\hline Extreme heat stress & 32 & 0,74 & 51 & 1,2 \\
Strong heat stress & 187 & 4,34 & 144 & 3,3 \\
Moderate heat stress & 426 & 9,86 & 192 & 4,4 \\
Slight heat stress & 580 & 13,42 & 277 & 6,4 \\
No thermal stress & 529 & 12,23 & 438 & 10,1 \\
Slight cold stress & 744 & 17,23 & 838 & 19,4 \\
Moderate cold stress & 636 & 14,73 & 992 & 23,0 \\
Strong cold stress & 574 & 13,30 & 800 & 18,5 \\
Extreme cold stress & 612 & 14,16 & 589 & 13,6 \\
\hline
\end{tabular}

Considering HEAT STRESS as the addition of (Extreme heat stress) + (Strong heat stress) + (Moderate heat stress), it was concluded that there was HEAT STRESS $15 \%$ of the time in location A (where no shadowing is available) and only $9 \%$ of the time in location B. However it is interesting to notice that extreme heat stress hours are very low in both locations but slightly higher in location B. Looking at specific simulation results it was concluded that this is due to the fact that, as shadowing is only partial, when solar radiation was not blocked and temperature was high (aprox. in the mornings from11:00 to 15:00, during may and june.) 
PET was, sometimes, higher because wind speed (that usually improves thermal comfort in hot periods) was partially reduced by the trees.

In Figure 4 it has been included the comparison of PET and black globe temperature (January - June 2019, hourly values):

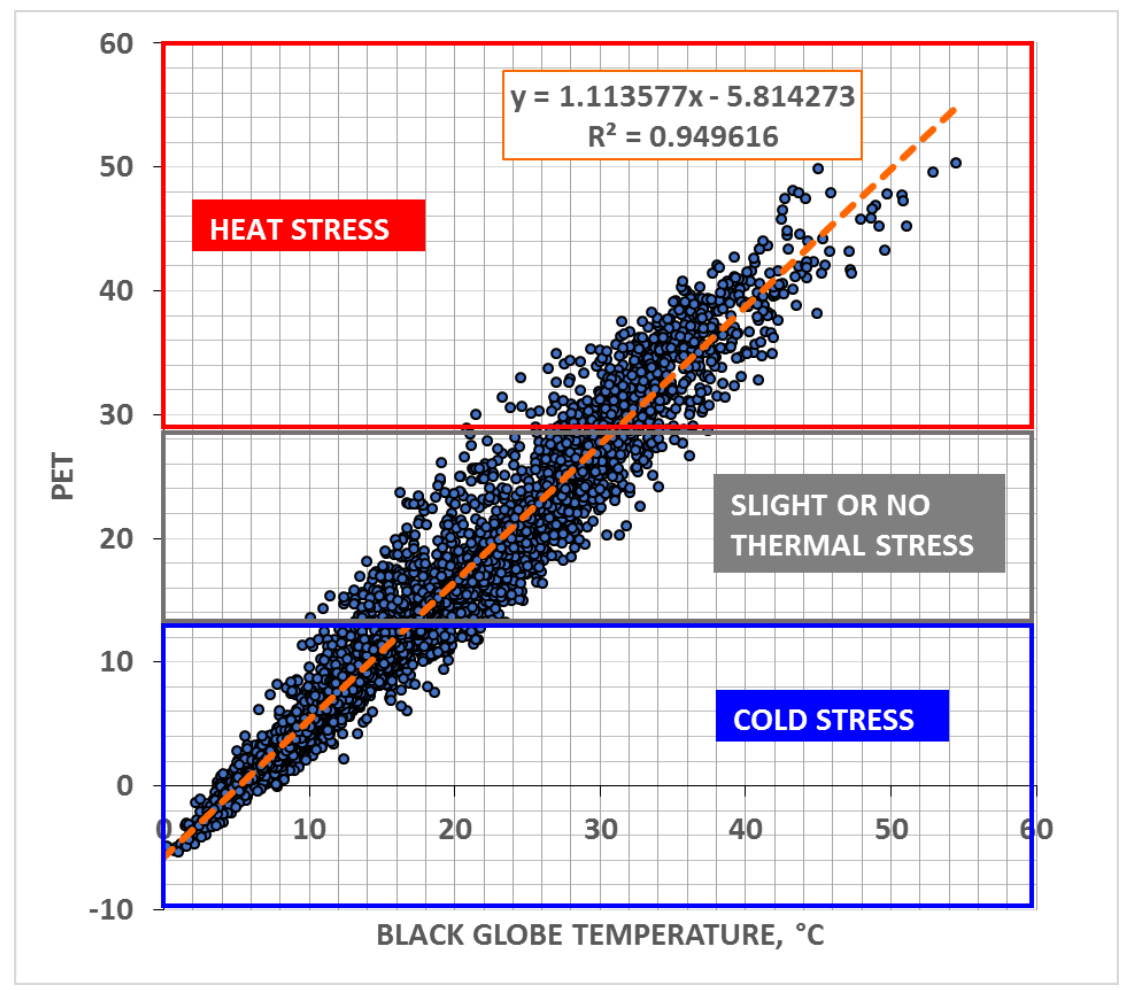

Figure 4. PET and Black globe temperature comparison

It can be concluded that there is an strong relationship and using linear approximation (other equations where tested but fitting was no improved significantly), it was observed an average error of 1.7 degree (with standard deviations of about 1.5 degrees, so most values with an error lower than 3.2 degrees) when calculating PET only with black globe temperature.

\section{Conclusions}

Monitoring of heat stress was performed in Valencia from January to June 2019 in two different urban locations. RAYMAN simulations provided PET values and it was concluded that $9-15 \%$ of the time there was heat stress. For accurate PET modelling it was necessary many outdoor conditions parameters (temperature, wind, 
humidity, solar radiation) however, based on preliminary results, acceptable approximations (average error or 1.7 PET degrees for absolute values in the range 20 - 50 PET degrees) can be done using just one metering variable, which is black globe temperature. However, more different locations and longer monitoring periods will be necessary to confirm these results.

\section{Acknowledgements}

This work was supported by European Commission through GROW GREEN project (Agreement number: 730283 — GROW GREEN — H2020-SCC-2016-2017/H2020-SCCNBS-2stage-2016. http://growgreenproject.eu/)

This work was supported in part by the regional public administration of Valencia under the grant ACIF/2018/106.

\section{References}

Oke, T.R. (1982). The energetic basis of the urban heat island. Q. J. R. Meteorol. Soc. 1982, 108, 1-24.

Rosenzweig, C.; Solecki, W.D.; Hammer, S.A.; Mehrotra, S. (2017). Climate Change and cities First Assessment Report of the Urban Climate Change Research Network. Available online: http://uccrn.org/files/2015/01/ARC3-Frontmatter-Final.pdf (accessed on 12 February 2017).

Blumberg, G. (2014). Assessing the Potential Impact of Heat Waves in Cities: Implications for Hazard Preparation and Planning. Procedia Econ. Financ. 18, 727-735.

European Environment Agency (2012). Urban Adaptation to Climate Change in Europe; European Environment Agency: Copenhagen, Denmark, 2012.

Matzarakis, A., Mayer, H., Iziomon, M.G., 1999. Applications of a universal thermal index: physiological equivalent temperature. Int. J. Biometerol. 43, 76-84.

Matzarakis, A., Endler, C., 2010. Climate change and thermal bioclimate in cities:impacts and options for adaptation in Freiburg, Germany. Int. J. Biometeorol. 54,479-483.

Matzarakis, A., Rutz, F., Mayer, H., 2007. Modelling radiation fluxes in simple and complex environments: application of the RayMan model. Int. J. Biometeorol. 51, 323-334.

Matzarakis, A., Rutz, F., Mayer, H., 2010. Modelling radiation fluxes in simple and complex environments: basics of the RayMan model. Int. J. Biometeorol. 54, 131-139. 